\title{
EXPERIMENTAL STUDY ON BOND PERFORMANCE OF GFRP BARS IN SELF-COMPACTING STEEL FIBER REINFORCED CONCRETE
}

H. Mazaheripour ${ }^{1}$, J. A. O. Barros ${ }^{2}$, J.M. Sena-Cruz ${ }^{3}$, M. Pepe ${ }^{4}$, E. Martinelli ${ }^{5}$

\begin{abstract}
Reinforcing bars made of Glass-Fiber-Reinforced Polymers (GFRP) are more and more common as internal reinforcement of concrete structures and infrastructures. Since the design of GFRP reinforced concrete members is often controlled by serviceability limit state criteria (i.e., deflection or crack width control), an accurate knowledge of the GFRP-concrete bond behavior is needed to formulate sound design equations. Furthermore, bond laws currently available and widely accepted for conventional steel rebars cannot be straightforwardly applied for GFRP ones. Hence, an experimental program consisting of 36 pullout bending tests was carried out to evaluate the bond performance between GFRP bars and steel fiber reinforced self-compacting concrete (SFRSCC) by analyzing the influence of the following parameters: GFRP bar diameter, surface characteristics of the GFRP bars, bond length, and SFRSCC cover thickness. Based on the results obtained in this study, pullout failure was occurred for almost all the specimens. SFRSCC cover thickness and bond length plaid important role on the ultimate value of bond stress of GFRP bars. Moreover, the GFRP bars with ribbed and sand-coated surface treatment showed different interfacial bond behaviors.
\end{abstract}

Keywords: GFRP, fiber reinforced concrete, bond, pullout bending test

\footnotetext{
${ }^{1}$ ISISE, PhD student of the Structural Division of the Dep. of Civil Engineering, University of Minho, 4800-058 Guimarães, Portugal.

${ }^{2}$ ISISE, Full Professor of the Structural Division of the Dep. of Civil Engineering, University of Minho, 4800058 Guimarães, Portugal.

${ }^{3}$ ISISE, Associate Professor of the Structural Division of the Dep. of Civil Engineering, University of Minho, 4800-058 Guimarães, Portugal.

${ }^{4} \mathrm{PhD}$ student of Structural Engineering, Dep. Civil Engineering, University of Salerno, Fisciano, Italy.

${ }^{5}$ Assistant Professor of Structural Engineering, Dep. of Civil Engineering, University of Salerno, Fisciano, Italy.
} 


\section{INTRODUCTION}

Steel bars in aggressive environmental conditions are generally affected by corrosion, which is often responsible for deterioration and damage processes developing in reinforced concrete $(\mathrm{RC})$ members. The reduction of the cross sectional area of these bars and the loss of bond to the surrounding damaged concrete can compromise the functionality of RC structures, or even their structural stability. Since the rehabilitation of corroded RC structures is generally an expensive solution, demolition of such structures is a relatively frequent option, though resulting in several unfavorable impacts in terms of economic, social and environmental aspects. In the last two decades, fiber reinforced polymer (FRP) bars have been introduced as a corrosion-free elements for reinforcing concrete structures and to get rid of the degradation phenomena generally induced by oxidation and corrosion of steel rebars.

However, as a result of the lower axial stiffness of FRP bars with respect to conventional steel ones, and diverse surface treatments they can present, the accomplishment of the serviceability limit state requirements becomes the governing design aspect for composite reinforced concrete members, especially in case of GFRP (glass) and AFRP (aramid) bars [1-5]. Thus, the available design rules, originally formulated and currently adopted for conventional steel reinforcement, cannot be directly applied for FRP bars. Since the evaluation of crack width and spacing is fully based upon the knowledge of bond between FRP bar and concrete, the assessment of bond behavior of FRP bars is a key aspect.

Despite some research has been done in the evaluation of the bond behavior of FRP bar in concrete during the last decades [6-12], there is not yet a formulation that has a large acceptation of the technical and scientific communities for the prediction of the bond behavior between FRP bars and surrounding concrete medium. In contrast to steel, FRP bar has also no standardization for surface treatments. Furthermore, many authors reported that the surface characteristics (sand-coated, indented, ribbed, helical or wrapping) of FRP bar strongly affect the bond stress between FRP and concrete $[6,8,12-16]$. Therefore, the bond behavior of FRP bar also depends on its surface treatment. Several experimental investigations have been carried out on the interfacial bond behavior of FRP bars, and a large number of parameters have been analyzed in this context to unveil their possible influence on the FRP-concrete bond behavior. According to [7, 12] the average bond stress tends to decrease with the increase of the FRP bar diameter. It is also verified that the maximum bond stress increases with the concrete 
compressive stress $[6,8,11,12,14]$. The position of the FRP bar during the casting process seems to play a relevant role in the bond performance [6].

The direct pullout test (with centric or eccentric position of bar), the beam test, the splice test and the ring pullout test are the most widely used to evaluate the bond behavior, being the direct pullout test the most frequent [6, 916]. Figure 1 shows a schematic representation of these test setups. Despite the direct pullout test has been used to compare the effectiveness of relevant bond parameters, such is the case of bar diameter, bar surface treatment, and concrete strength, the obtained results are affected by the confinement applied to the surrounding concrete during the pullout process [10]. Due to a similar compression action on the surrounding concrete at the loaded end applied by the specimen's supporting system, this confinement type effect can also affect the obtained results in the ring pullout test (Figure 1b). These setups, therefore, do not replicate the bond conditions of a reinforcing system in a real concrete element. Hence, to avoid the influence of concrete confinement, beam test (or splice test) has also been used. Tighiouart et al. [7] carried out an experimental program consisting of direct pullout and beam tests by using two types of GFPR bars, and these bars presented bond stress values lower than steel bars [7]. Pecce et al. [8] also conducted an experimental study based on a modified beam test setup, and they verified that the loaded end slip increased with the embedment length. Both studies [7, 8] used commercial available GFRP bars, but the influence of concrete cover on the bond behavior was not investigated.

The present study is part of a research project that has the purpose of developing high performance fiber reinforced concrete (HPFRC) beams flexurally reinforced with a hybrid system composed of pre-stressed GFRP bars placed as close as possible to the tensile surface of the beam, and pre-stressed steel bars protected by a thicker HPFRC cover to achieve enough protection to corrosion phenomena. The HPFRC should be designed in order to provide enough shear resistance for avoiding the use of steel stirrups. The HPFRC has also the purpose of enhancing the bond properties between bars and concrete. In the present phase of the project, a steel fiber reinforced self-compacting concrete (SFRSCC) was adopted, since available research indicates that this cement composite is a favorable medium in terms of bond performance for flexural reinforcements [17]. Hence, an experimental program was conducted to evaluate bond behavior between GFRP bars and SFRSCC by carrying out pullout bending tests (similar to that recommend by RILEM [18]). The effect of GFRP bar diameter, surface characteristics of the GFRP bars, bond length, and concrete cover thickness on the bond behavior was assessed. 


\section{EXPERIMENTAL PROGRAM}

In the present experimental program, a total of 36 pullout bending tests were carried out to evaluate the bond behavior of two types of GFRP bars supplied by European companies. The tests were conducted at the laboratory of the Structural Division of the Civil Engineering Department of University of Minho, Portugal.

\subsection{Material properties}

\subsubsection{GFRP bars}

Two types of GFRP bar in terms of surface treatment were used in this study, and the designation of type A and type B was assumed for deformed and smooth bars, respectively. The ribs of the deformed surface of type A bar have a constant height of $6 \%$ of bar diameter and a spacing of about $8.5 \mathrm{~mm}$. Spherical natural quartz-crystal sand with triangular structure was used for sand-coating in type B bar. The mechanical properties of bars based on the information provided by the manufacturers are included in Table 1. A tensile strength higher than 1000 MPa was indicated for both types of bar, while values of 60 and $40 \mathrm{GPa}$ were suggested for the modulus of elasticity of type A and type B bar, respectively. Direct tensile tests were carried out to obtain the modulus of elasticity, and the values also indicated in Table 1 were obtained following the recommendations of ASTM D 7205/D 7205M [19]. Two diameters, 8 and $12 \mathrm{~mm}$, were adopted for type A bar, while only one diameter (12 $\mathrm{mm}$ ) was considered for type B bar (see Figure 2). The obtained values for the modulus of elasticity of both types of bars were higher than those provided by the company; exceptionally, when the diameter measured in the bar was considered for $\$ 12$ type A (13.08 $\mathrm{mm}$ instead of $12 \mathrm{~mm}$ ), the value of the modulus of elasticity (56 GPa) was lower than $60 \mathrm{GPa}$ reported by the supplier.

\subsubsection{Concrete}

For the present phase of the research project, a self compacting concrete reinforced with $60 \mathrm{~kg} / \mathrm{m}^{3}$ of hooked end steel fibers was used to build the pullout bending specimens. The mix of this concrete is included in Table 2 . Ordinary Portland cement produced according to the standard EN 197-1:2000 and labeled as CEM I 42.5 R, fine and coarse river sand and crushed granite gravel aggregate with maximum size of $12 \mathrm{~mm}$ were used, and the 
water/cement ratio was 0.39 . Optimized amount of $1.9 \%$ superplasticizer was adopted to contribute for the attainment of self-compacting requisites for the mix. Hooked end steel fibers of $33 \mathrm{~mm}$ length $\left(l_{f}\right), 0.55 \mathrm{~mm}$ diameter $\left(d_{f}\right)$, aspect ratio of $60\left(l_{f} / d_{f}=60\right)$, and a tensile strength of about $1100 \mathrm{MPa}$ were used. The concrete mixture showed good homogeneity and cohesion, and the total spread measured in the slump-flow tests [20] ranged between 680 and $720 \mathrm{~mm}$, with no visual sign of segregation.

The SFRSCC compressive strength was determined according to ASTM C39 with cylinder samples taken from all batches (three cylinders with $150 \mathrm{~mm}$ diameter and $300 \mathrm{~mm}$ height for each batch). Prior to those tests, three cylinders were used to determine the Young's modulus of SFRSCC according to ASTM C469. A total number of five beams with dimensions of $600 \times 150 \times 150 \mathrm{~mm}^{3}$ were also cast to determine the flexural tensile strength and the flexural residual strength parameters of SFRSCC according to the recommendations of RILEM [21]. The average value of the Young's modulus and flexural tensile strength of SFRSCC were $30.36 \mathrm{GPa}$ with a coefficient of variation $(\mathrm{CoV})$ of $15.48 \%$, and $6.28 \mathrm{MPa}(\mathrm{CoV}=17.48 \%)$, respectively (see Table 3). The results from the full characterization of the SFRSCC are available elsewhere [22]. The average compressive strength for the five SFRSCC batches has varied from 58.58 to 67.58 MPa (Table 3).

Since to produce all the specimens for the pullout bending program it was necessary to execute five batches, the mechanical properties of SFRSCC from those batches were slightly different. Assuming that bond stress (and concrete tensile strength) can be related to the square root of compressive strength, the differences were taken into account by correcting the bond values by applying the following bond modified factor $\gamma_{i}$ :

$$
\gamma_{i}=\sqrt{\frac{f_{c m r}}{f_{c m i}}}, \quad(i=1,2, \ldots, 5)
$$

where $f_{\mathrm{cmi}}$ is the average compressive strength of the $i^{\text {th }}$ concrete batch, and $f_{\mathrm{cmr}}$ is the reference value. Assuming for the $f_{\mathrm{cmr}}$ the average compressive strength of SFRSCC of the batch used to produce the first series of pullout specimens (M1), the values of the bond modified factor are those included in Table 3.

\subsection{Test procedure}

\subsubsection{Specimens}


A beam test similar to the one recommended by RILEM [18] was adopted in this study for determining local pullout force-slip relationships. A schematic representation of the specimen is shown in Figure 3a. The specimen is composed of two prismatic SFRSCC blocks, A and B, which are connected by a GFRP bar as a flexural reinforcement at bottom part, and a steel hinge at top zone. Type of bars, SFRSCC cover thickness, embedment length $\left(L_{e}\right)$ and bar diameter varied in those specimens in order to assess their influence in the GFRP-SFRSCC bond behavior. In the front part of each block, in a length of $50 \mathrm{~mm}(75 \mathrm{~mm}$ from the symmetry axis) the bar is unbonded to avoid premature fracture of SFRSCC in these zones. The $L_{e}$ was only changed in the block A (where debonding failure is supposed to develop), while in the block B a constant embedment length of $335 \mathrm{~mm}$ was considered for all specimens. Plastic tubes of very low elasticity modulus and without bond requisites to cement-based materials were used to involve the GFRP bars for providing un-embedded lengths between concrete and GFRP bars.

The specimens are identified by assuming the following labels: the first letter, A or B, indicates the type of bar surface; the second set of symbols refers the bar diameter ( $\phi 8$ or $\phi 12)$; the third one, denoted as LX $\phi$, symbolizes the embedment length, being $X$ the multiple of the bar diameter $(X=5,10$ and 20); the fourth label represents the concrete cover thickness, $15 \mathrm{~mm}(\mathrm{C} 15)$ or $30 \mathrm{~mm}(\mathrm{C} 30)$; and the last set is a regular counting of the specimens. For example, the label A- $\phi 8-\mathrm{L} 10 \phi-\mathrm{C} 30-07$ corresponds to the specimen number 7 reinforced with a ribbed surface type A bar of $8 \mathrm{~mm}$ diameter $(\phi 8)$, with an embedment length of $80 \mathrm{~mm}(10 \phi=10 \times 8 \mathrm{~mm})$, and with a concrete cover of $30 \mathrm{~mm}(\mathrm{C} 30)$.

\subsubsection{Test setup and measuring devices}

Figure $3 \mathrm{~b}$ shows the test setup configuration used in this study. To measure the slip at loaded and free ends of GFRP bar, two linear variable differential transducers, LVDT_1 and LVDT_2, were used. LVDT_1 is supported on the bar at its free end, and measures the relative displacement between this section and the concrete front surface of the block A (see Figure 3b), while LVDT_2 is fixed to the free extremity of the bar and measures the relative displacement between the free end part of the bar and the concrete rear surface. As shown in Figure 3b, a strain gauge was installed in the cross section of the bar coinciding with specimen symmetry axis to record the strains in the bar during the test. Three load cells with capacity of $200 \mathrm{kN}$ were utilized to determine the applied load in each contact point of the specimen with the exterior. Two of these load cells are disposed according to 
the scheme represented in Figure $3 b$, while the third was coupled to the actuator. The pullout force $(F)$ was calculated by multiplying the evaluated average elasticity modulus $\left(E_{b}\right)$ of the bar by the strain recorded in the strain gauge $\left(\varepsilon_{b}\right)$ and considering the measured cross sectional area of the bar $\left(A_{b}\right), F=A_{b} E_{b} \varepsilon_{b}$ (see also Table 1). The force installed in the bar was also calculated by equilibrium between the applied loads and the corresponding reactions to the specimen. The change of the arm (distance between hinge connection point and the center of the bar) at mid-span was measured by two vertical LVDT's installed in the first 12 specimens (for all $5 \phi$ bond length specimens). The force values derived from both methods showed negligible differences, so the one based on measuring the strains in the GFRP bars was adopted for all the tested specimens.

Due to the elastic elongation of GFRP bar between the loaded end section (coinciding with the Point $\mathrm{x}$ indicated in Figure 3b) and the measuring section of LVDT_1 (front face of the concrete block A), the slip at loaded end $\left(s_{l p}\right.$, in $\left.\mathrm{mm}\right)$ was obtained by deducing from the displacement measured by the LVDT_1 $\left(s_{\mathrm{LVDT} 1}\right.$, in mm $)$ the elastic deformation in this segment of the bar $\left(50 \varepsilon_{\mathrm{b}}\right.$, in $\left.\mathrm{mm}\right)$ :

$$
s_{l p}=s_{\mathrm{LVDT} 1}-50 \varepsilon_{\mathrm{b}}
$$

where $\varepsilon_{b}$ is the strain in the FRP bar measured by the strain gauge.

The tests were carried out by using a closed-loop hydraulic system with a servo actuator of $200 \mathrm{kN}$ capacity. Two loading phases of different slip rate were adopted by using LVDT_1 for test control: $3 \mu \mathrm{m} / \mathrm{s}$ up to $5 \mathrm{~mm}$ slip; $5 \mu \mathrm{m} / \mathrm{s}$ up to the end of the test.

\section{TEST RESULTS AND DISCUSSION}

Tables 4 and 5 show the results of GFRP bar type A and B, respectively, obtained from the pullout bending tests. These tables include the maximum pullout force, $F_{\max }$, the corresponding slip at loaded $\left(s_{l p}\right)$ and free $\left(s_{f p}\right)$ ends, maximum average bond stress assuming that bond stresses are constant along the embedment length $\left(\bar{\tau}_{\max }\right)$, modified bond stress normalized by using $\gamma_{i}$ coefficient, and failure mode. The relationships between the pullout force and the slip at loaded end $\left(F-s_{l}\right)$ and free end $\left(F-s_{f}\right)$ are plotted in Figures 4 to 6 . In general, the pullout force versus slip responses are characterized by a short linear branch, in which damage in the debonding process is not sufficiently intense to produce irreversible slip, followed by a nonlinear response up to peak load due to the increase of the damage. The post peak phase is characterized by a soft decrease of the pullout force with the 
increase of slip. The tests end with a relatively high residual pullout force due to the friction resistance between the GFRP and SFRSCC. As expected, these figures show that the peak pullout force and its corresponding slip increase with the embedment length. Furthermore, at peak load the free end slip is non null in all specimens, confirming that the embedment length is not enough, even for $L_{e}=20 \phi$, in order to mobilize the tensile capacity of the utilized GFRP bars.

\subsection{Failure modes}

Due to the relative high pullout force supported by specimens reinforced with the larger bar diameter and embedment length, the specimens number 17, 24, 29 and 31 failed due to insufficient shear resistance of SFRSCC. To avoid this type of failure mode, carbon fibre reinforced polymer (CFRP) laminates were applied in the lateral faces of the specimens, according to the near surface mounted technique [23], in locations that do not affect the GFRP-SFRSCC bond behaviour. Thus, except specimen number 12 (A- $\phi 8-L 20 \phi-C 30-12$ ), the remaining ones failed by debonding. In case of ribbed bars (type A) with concrete cover of $15 \mathrm{~mm}$ (specimens number 18, 21 and 22) a single crack appeared along the embedment length. This crack had naturally a detrimental effect on the bond performance of these specimens, since the concrete confinement decreases with the increase of the opening of this crack. However, splitting failure mode never occurred due to the contribution of fibers bridging this crack that had maintained the crack width at very small value.

According to [12], for concrete of compressive strength higher than $30 \mathrm{MPa}$, bond failure partly occurs on the surface of the bar and partly in the concrete by peeling the cortical layer of the bar. Since a relatively high concrete compressive strength was used in this study (>50 MPa), the bond failure mode significantly depends upon the surface treatment of FRP bars. The block A of each specimen was cut after testing in order to have a deeper inspection of the failure mode. Figure 7a shows the damages on surface of GFRP bars after testing. The resin over the surface of GFRP bar was chopped and crushed in case of type B, and the ribs were scratched in the type A bars. However, in the type A bar of specimens where a single splitting crack was formed, signs of concrete damage was observed at the bottom of the bar's surface due to the lower confinement provided by the cracked concrete cover. This means that the bond failure for these specimens was controlled by both type of failure modes at the top and bottom of the GFRP-SFRSCC interface (see Figure 7b). 
This mixed damage configuration was more prone in the bars of higher flexural stiffness surrounded by smaller SFRSCC cover thickness, since the curvature of the GFRP bar along the embedment length increases with the reduction of the SFRSCC cover thickness (more deformable medium). This favors the increase of the radial stresses applied by the concrete to the top surface of the bar, and due to the Mohr-Coulomb effect the shear stresses increase, leading to the scratch of the ribs of the bar in these zones. Furthermore, due to the intrinsic nature of concrete casting conditions, at the bottom part of the bar a higher percentage of porous and flaws exist. Therefore, the combination of the smaller strength of this material with the local radial stresses due to the curvature of the bar justifies the presence of this cement paste material in between the GFRP ribs at the bottom part of the bar.

\subsection{Bar diameter}

Figure 8 compares the bond performance of $8 \mathrm{~mm}$ and $12 \mathrm{~mm}$ GFRP type A bars in terms of $\bar{\tau}_{\text {max }}$. For the specimens with $15 \mathrm{~mm}$ of SFRSCC cover, the maximum bond stress achieved in the case of $12 \mathrm{~mm}$ bar diameter was almost equal or even smaller than the corresponding $\bar{\tau}_{\max }$ obtained for $8 \mathrm{~mm}$ bar. However, in the specimens with $30 \mathrm{~mm}$ of SFRSCC cover, the maximum bond stress $\left(\bar{\tau}_{\mathrm{max}}\right)$ for a bar diameter of $12 \mathrm{~mm}$ was higher than for the $8 \mathrm{~mm}$ with exception of $20 \phi$ embedment length. It is worth noting that, this trend decreased with the increase of $L_{e}$. By increasing the bar diameter and the bond length the maximum pullout force was conditioned by the splitting strength capacity of SFRSCC cover, which increased with the SFRSCC cover thickness.

\subsection{Concrete cover}

Figure 9 represents the increase in the $\bar{\tau}_{\max }$ for the specimens with $30 \mathrm{~mm}$ SFRSCC cover thickness with respect to the corresponding values obtained for $15 \mathrm{~mm}$ SFRSCC cover. This analysis was executed for the three types of bars and for the different $L_{e}$ values considered. The results show higher maximum average bond stress when $30 \mathrm{~mm}$ SFRSCC cover thickness was used, with the exception of the $8 \mathrm{~mm}$ bar diameter with $5 \phi$ embedment length, since in this case the relatively low pullout force is not influenced by the splitting strength of the SFRSCC cover. 
The values of $\bar{\tau}_{\max }$ were also higher in case of ribbed bars (type A) than in sand-coated bars (type B), which reveals the influence of the surface treatment and bar stiffness (the type A bar has higher elasticity modulus and measured diameter, see Table 1). Since the type B bar has a lower elasticity modulus and, consequently, lower stiffness, apart the effects pointed out in the last paragraph of Section 3.1, the higher contraction of the bar in the plane of its cross section due to the Poisson's effect is expected to have contributed for the smaller performance of the type B bar. The better performance of the specimens with $30 \mathrm{~mm}$ SFRSCC cover can be explained by the higher volume of concrete surrounding the bar that promotes the superior confinement, and smaller damage in the concrete cover.

The average residual bond stress, $\bar{\tau}_{\text {res }}$ is another important parameter characterizing the pseudo-ductility of the bond behavior. $\bar{\tau}_{\text {res }}$ was calculated for a pullout force corresponding to a relatively high value of loaded end slip $(8 \mathrm{~mm})$, when the debonding process is in the post-peak pullout force for all the specimens. Figure 10 reports the ratio between $\bar{\tau}_{\text {res }}$ and $\bar{\tau}_{\text {max }}$ for the type of bars, bar diameter, and SFRSCC cover, where it is visible that the $\bar{\tau}_{\text {res }} / \bar{\tau}_{\max }$ ratio increases with concrete cover.

\subsection{Embedment length}

Figure 11a shows the evolution of the maximum average bond stress with the embedment length $\left(L_{\mathrm{e}}\right)$. As expected, $\bar{\tau}_{\max }$ decreased with the increase of $L_{e}$, which is a consequence of the nonlinear distribution of the bond stress along $L_{e}$ [7]. As shown in Figure $11 \mathrm{~b}$, the loaded end slip at peak pullout force $\left(s_{l p}\right)$ increased with $L_{e}$ and bar diameter. The increase of $s_{l p}$ with $L_{e}$ is a natural consequence of the increase of the maximum pullout force with the increase of $L_{e}$, and the similar stiffness of the $F$ - $s_{l}$ pre-peak phase for the different $L_{e}$ test series (Figures 4 to 6). The increase of $s_{l p}$ with $L_{e}$ was more pronounced in bars of ribbed surface (type A) than in bars of sand coated surface (type B). In fact, the $s_{l p}$ was higher in type B bar for the smallest $L_{e}$, almost equal in both types of bars for the intermediate $L_{e}$, and smaller in type $\mathrm{B}$ bar for the largest $L_{e}$. On the other hand, no significant variation was observed in terms of free end slip at peak pullout force $\left(s_{f p}\right)$ by increasing $L_{e}$ (see Figure 11b). However, the free end slip in type B bar was considerably smaller than in type A (0.09 mm against 0.24 $\mathrm{mm}$ ), which is a consequence of the larger damage introduced by the stiffer type bar A along the embedment length, as already reported in previous sections. 


\subsection{Surface treatment}

Figure 12a shows that $\bar{\tau}_{\max }$ was larger in ribbed GFRP bars (type A) than in sand coated GFRP bars (type B), regardless the bar embedment length and concrete cover. Figure $12 \mathrm{~b}$ represents a comparison between the pullout force versus loaded end slip up to $s_{l p}=2 \mathrm{~mm}$, for type A and type B bar, in case of 15 and 30 mm concrete cover thickness. Figure 12b clearly shows that type A bar had a higher bond stiffness and peak pullout force than type B bar, which is not only a consequence of the surface characteristics of these bars, but also the larger stiffness of the type A bar (larger determined elasticity modulus and measured diameter, Table 1), as already indicated. The higher pullout force in the post-peak phase evidenced by the type A bar (Figure 12b) can also be a consequence of the higher frictional resistance provided by the ribbed surface characteristics of this type of bar. In Figure 13 is compared the relationship between the average strain in the bar at the load end and the slip at this loaded end section $\left(\varepsilon_{b}-s_{l}\right)$ up to peak pullout force for type bar A and B. For this purpose it was selected bars of $12 \mathrm{~mm}$ diameter with $L_{e}=5 \phi$, but the obtained trends are representative of the behaviour registered in the other analyzed cases. This figure shows that for any average strain in the loaded end section, the type bar B always presented a higher loaded end slip, regardless the concrete cover thickness. This discrepancy between both types of bars increased during the loading process, and was higher in the specimens of smaller concrete cover.

\section{CONCLUSION}

The bond performance between two types of GFRP bars and steel fiber reinforced self-compacting concrete (SFRSCC) was investigated by performing thirty-six pullout bending tests. The influence of bar diameter (8 $\mathrm{mm}$ and $12 \mathrm{~mm}$ ) and surface configuration (ribbed versus sand-coated), concrete cover thickness (15 mm and $30 \mathrm{~mm})$, and bar embedment length $(5 \phi, 10 \phi$ and $20 \phi$, where $\phi$ is the bar diameter $)$ on the bond performance was investigated. From the obtained results the following main remarks can be pointed out.

In general the specimens failed by debonding, indicating that the bond length to attain the ultimate tensile strength of the bars is higher than $20 \phi$ for the two types of GFRP bars when embedded in the adopted SFRSCC. 
For the specimens with a concrete cover of $15 \mathrm{~mm}$, mainly in those of higher bar diameter, a single crack was formed in the alignment of the bars, which had a detrimental effect on the bond performance of these specimens. However, splitting failure never occurred because fiber reinforcement mechanisms avoided the degeneration of micro into macro-cracks. Therefore, it is expectable that using higher content of fibers, or also adding fibers of high aspect ratio, the cover thickness of $15 \mathrm{~mm}$ can be enough for this type of bars, but more research need to be carried out in this respect.

By observing the surface of the bars after the experimental tests it was concluded that the bond failure was, in general controlled by the shear resistance of GFRP surface layers. However, in the type A bar of specimens where a single splitting crack was formed, a mixed damage configuration in the bar was observed, with scratched ribs on the top surface of the bar and inclusions of cement paste in between the GFRP ribs at the bottom part of the bar. This type of failure mode was more prone in the bars of higher flexural stiffness surrounded by smaller concrete cover thickness.

By increasing the bar diameter and the bond length, the maximum pullout force become limited by the SFRSCC splitting strength, which increased with the concrete cover thickness. The concrete cover had, in fact, an important role on the bond behaviour of GFRP-SFRSCC, since the maximum average bond shear stress, $\bar{\tau}_{\max }$, for both types of GFRP bars (smooth and ribbed surface) increased with the SFRSCC cover.

By increasing the concrete cover the post-peak pullout force increased, and consequently the average residual bond stress as well, which contributes for a better bond behavior by reducing crack width and crack spacing. The higher pullout force in the post-peak phase evidenced by the type A bar can also be a consequence of the higher frictional resistance provided by the ribbed surface characteristics of this type of bar.

The loaded end slip at peak pullout force $\left(s_{l p}\right)$ increased with both $L_{e}$ and bar diameter. The increase of $s_{l p}$ with $L_{e}$ was more pronounced in the ribbed bars (type A) than in sand coated bars (type B). Type A bar had a higher bond stiffness and peak pullout force than type B bar, which is not only a consequence of the surface characteristics of these bars, but also the larger stiffness of the type A bar. 


\section{ACKNOWLEDGEMENT}

This work is supported by FEDER funds through the Operational Programme for Competitiveness Factors COMPETE and National Funds through FCT - Portuguese Foundation for Science and Technology under the project PTDC/ECM/105700/2008 - "DURCOST - Innovation in reinforcing systems for sustainable prefabricated structures of higher durability and enhanced structural performance". The authors also thank the collaboration of the following companies: Sireg and Schoeck for providing the GFRP bars, Casais to manufacture the moulds, Maccaferri for supplying the steel fibers, Secil/Unibetão for providing the Cement, SIKA for supplying the superplasticizers; CiviTest for the production of SFRSCC specimens.

\section{REFERENCES}

[1] Almusallam TH. Analytical prediction of flexural behavior of concrete beams reinforced by fiber reinforced polymer (FRP) bars. J Compos Mater 1997;31(7):640-57.

[2] Masmoudi R, Theriault M, Benmokrane B. Flexural behavior of concrete beams reinforced with deformed fiber reinforced plastic reinforcing rods. ACI Struct J 1998;95(6):665-76.

[3] Abdalla HA, Evaluation of deflection in concrete members reinforced with fiber reinforced polymer (FRP) bars. Composite Structures 2002;56(1):63-71.

[4] Pecce M, Manfredi G, Cosenza E. Experimental response and code models of GFRP RC beams in bending. J Compos Constr 2000;4(4):182-90.

[5] Taheri M, Barros JAO, Salehian HR. A parametric study on the use of strain softening/hardening FRC for RC elements failing in bending, Mater Civ Eng J 2012; DOI: 10.1061/(ASCE)MT.1943-5533.0000373. (in press) 
[6] Rossetti VA. Local bond stress-slip relationships of glass fiber reinforced plastic bars embedded in concrete. Mater Struc 1995;28(6):340-344.

[7] Tighiouart B, Benmokrane B, Gao D. Investigation of bond in concrete member with fiber reinforced polymer (FRP) bars. Constr Build Mater 1998;12(8):453-462.

[8] Pecce M, Manfredi, G, Realfonzo R, Cosenza E. Experimental and analytical evaluation of bond properties of GFRP bars. J Mater Civ Eng 2001;13(4):282-290.

[9] Okelo R, A.M.ASCE, Yuan RL, P.E., M.ASCE. Bond Strength of Fiber Reinforced Polymer Rebars in Normal Strength Concrete. J. Compos for Constr 2005;9(3) 203-213.

[10] Aiello MA; Leone M; Pecce M. Bond Performances of FRP Rebars-Reinforced Concrete. J Mater Civ Eng 2007;19(3):205-213.

[11]Baena M, Torres L, Turon A, Barris C. Experimental study of bond behavior between concrete and FRP bars using a pull-out test. Compos Part B 2009;40(8):784-797.

[12] Achillides Z, Pilakoutas K. Bond Behavior of Fiber Reinforced Polymer Bars under Direct Pullout Conditions. J Compos Constr 2004;8(2):173-181.

[13] AL-mahmoud F, Castel A, Francois R, Tourneur C. Effect of surface pre-conditioning on bond of carbon fiber reinforced polymer rods to concrete. Cem Concr Compos 2007;29(9):677-689.

[14]Lee JY, Kim TY, Kim TJ, Yi CK, Park JS, You YC, Park YH. Interfacial bond strength of glass fiber reinforced polymer bars in high-strength concrete. Compos Part B 2008;39(2):258-270.

[15] Hao Q, Wang Y, He Z, Ou J. Bond strength of glass fiber reinforced polymer ribbed rebars in normal strength concrete. Constr Build mater 2009;23(2):865-871. 
[16] Katz A. Bond mechanism of FRP rebars to concrete. Mater Struc 1999;32(10):761-768.

[17] Schumacher P. Rotation capacity of self-compacting steel fiber reinforced concrete. PhD Thesis, Delft University, 2006.

[18] RILEM. Bond test for reinforcement steel 1. Beam test. 1982; TC9-RC.

[19]ASTM D7205/D7205M-06. Standard Test Method for Tensile Properties of Fiber Reinforced Polymer Matrix Composite Bars. ASTM International, US, 2006.

[20]EFNARC. The European guidelines for self-compacting concrete. Specification, production and use. 2005.

[21]RILEM TC 162-TDF: Test and design methods for steel fiber reinforced concrete. Materials and structures 2002; 35 579-582.

[22] Mazaheripour H, Barros J, Soltanzadeh F, Goncalves D. Interfacial bond behaviour of GFRP bar in self compacting Fiber Reinforced Concrete. In: Proceeding of 8th RILEM international symposium on fiber reinforced concrete: Challenges and Opportunities, Guimaraes, Portugal; 2012. (Accepted)

[23] Sena-Cruz JM, Strengthening of concrete structure with near-surface mounted CFRP laminate strips. PhD thesis. Guimaraes, University of Minho, 2004. http://hdl.handle.net/1822/11781 


\section{List of tables:}

3 Table 1 - The mechanical properties of GFRP bars

4 Table 2 - Composition of the SFRSCC

5 Table 3 - Properties of mix design

6 Table 4 - Bond test results of GFRP bar type A

$7 \quad$ Table 5 - Bond results of GFRP bar type B 
Table 1 - The mechanical properties of GFRP bars

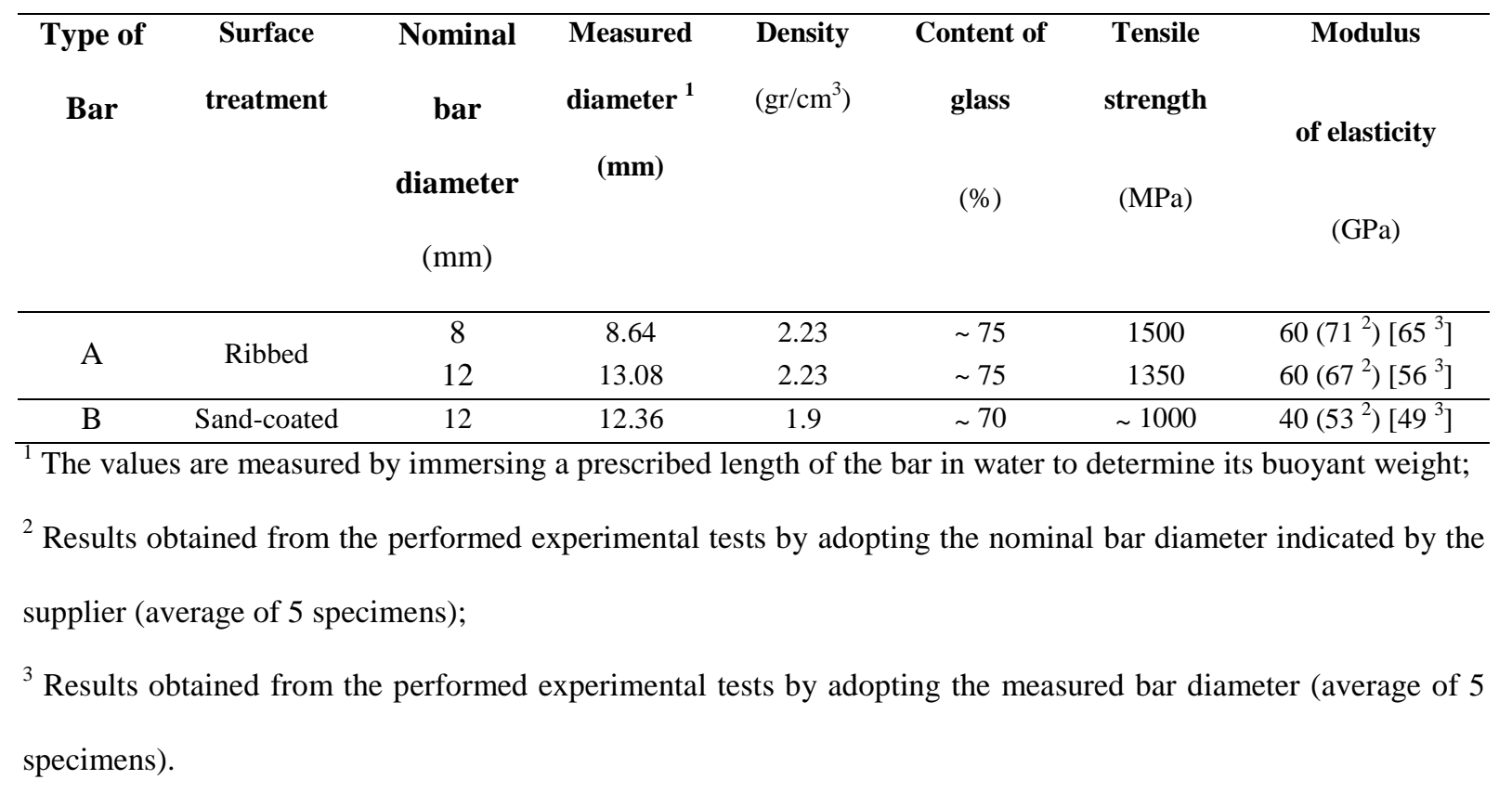


Table 2 - Composition of the SFRSCC

\begin{tabular}{ll}
\hline Components & Quantity \\
& $\left(\mathbf{k g} / \mathbf{m}^{\mathbf{3}}\right)$ \\
\hline Cement & 412 \\
Limestone filler & 353 \\
Fine river sand $(\mathbf{0 - 2 . 3 8} \mathbf{~ m m})$ & 179 \\
Coarse river sand $(\mathbf{0 - 4 . 7 6} \mathbf{~ m m})$ & 655 \\
Crushed granite $\mathbf{( 4 . 7 6 - 1 2 . 7 0 ~} \mathbf{~ m m})$ & 588 \\
Water & 160 \\
Superplastizier & 7.83 \\
Hooked end steel fibers & 60 \\
\hline
\end{tabular}


Table 3 - Properties of the SFRSCC batches

\begin{tabular}{|c|c|c|c|c|}
\hline Batch designation & $\begin{array}{c}\text { Compressive strength } \\
\text { (MPa) }\end{array}$ & $\begin{array}{c}\text { Flexural } \\
\text { tensile } \\
\text { strength } \\
\text { (MPa) }\end{array}$ & $\begin{array}{c}\text { Modulus of } \\
\text { elasticity } \\
\text { (GPa) }\end{array}$ & $\begin{array}{c}\text { Bond } \\
\text { modified } \\
\text { factor }^{*}, \\
\gamma_{i}\end{array}$ \\
\hline $\begin{array}{l}\text { M1 } \\
\text { M2 } \\
\text { M3 } \\
\text { M4 } \\
\text { M5 } \\
\end{array}$ & $\begin{array}{l}58.58(3.15 \%) \\
61.45(4.71 \%) \\
67.58(4.86 \%) \\
64.58(1.25 \%) \\
66.38(4.28 \%)\end{array}$ & $\begin{array}{c}6.28 \\
(17.48 \%)\end{array}$ & $\begin{array}{c}30.36 \\
(15.48 \%)\end{array}$ & $\begin{array}{l}1.00 \\
0.98 \\
0.93 \\
0.95 \\
0.94\end{array}$ \\
\hline
\end{tabular}

Note: the values between parentheses are the corresponding coefficients of variation; ${ }^{*}$ obtained from Eq. (1) 
Table 4 - Bond test results of GFRP bar (type A)

\begin{tabular}{|c|c|c|c|c|c|c|c|c|c|}
\hline \multirow[b]{2}{*}{ Specimen designation } & \multicolumn{3}{|c|}{ Concrete } & \multirow[b]{2}{*}{$\begin{array}{l}F_{\max } \\
(\mathbf{k N})\end{array}$} & \multirow[b]{2}{*}{$\begin{array}{c}s_{l p} \\
(\mathbf{m m})\end{array}$} & \multirow[b]{2}{*}{$\begin{array}{c}s_{f p} \\
(\mathbf{m m})\end{array}$} & \multirow[b]{2}{*}{$\begin{array}{c}\bar{\tau}_{\max } \\
\text { (MPa) }\end{array}$} & \multirow[b]{2}{*}{$\begin{array}{c}\text { Modified } \\
\text { bond } \\
\text { stress } \\
\text { (MPa) }\end{array}$} & \multirow[b]{2}{*}{$\begin{array}{l}\text { Failure } \\
\text { Mode }^{1}\end{array}$} \\
\hline & $\begin{array}{c}\text { Mix } \\
\text { design }\end{array}$ & $\begin{array}{c}f_{\mathbf{c}} \\
(\mathrm{MPa})\end{array}$ & $\gamma_{i}$ & & & & & & \\
\hline A- $\phi 8-L 5 \phi-C 15-01$ & M1 & \multirow{4}{*}{58.58} & \multirow{4}{*}{1.00} & 20.02 & 0.27 & 0.23 & 19.92 & 19.92 & $\mathrm{P}$ \\
\hline$A-\phi 8-L 5 \phi-C 15-02$ & M1 & & & 20.73 & 0.39 & 0.24 & 20.63 & 20.63 & $\mathrm{P}$ \\
\hline$A-\phi 8-L 5 \phi-C 30-03$ & M1 & & & 20.77 & 0.31 & 0.27 & 20.67 & 20.67 & $\mathrm{P}$ \\
\hline A- $\phi 8-L 5 \phi-C 30-04$ & M1 & & & 19.14 & 0.37 & 0.27 & 19.05 & 19.05 & $\mathrm{P}$ \\
\hline A- $\phi 8-L 10 \phi-C 15-05$ & M5 & \multirow{2}{*}{66.38} & \multirow{2}{*}{0.94} & 32.18 & 0.88 & 0.23 & 16.01 & 15.05 & $\mathrm{P}$ \\
\hline A- $\phi 8-L 10 \phi-C 15-06$ & M5 & & & 29.58 & 0.89 & 0.07 & 14.72 & 13.84 & $\mathrm{P}$ \\
\hline A- $\phi 8-L 10 \phi-C 30-07$ & M4 & \multirow{2}{*}{64.58} & \multirow{2}{*}{0.95} & 35.34 & 0.85 & 0.34 & 17.59 & 16.71 & $\mathrm{P}$ \\
\hline A- $\phi 8-L 10 \phi-C 30-08$ & M4 & & & 35.30 & 0.65 & 0.31 & 17.57 & 16.69 & $\mathrm{P}$ \\
\hline A- $\phi 8-L 20 \phi-C 15-09$ & M4 & \multirow{4}{*}{64.58} & \multirow{4}{*}{0.95} & 56.11 & 1.67 & 0.12 & 13.96 & 13.26 & $\mathrm{P}$ \\
\hline$A-\phi 8-L 20 \phi-C 15-10$ & M4 & & & 58.18 & 1.46 & 0.11 & 14.47 & 13.74 & $\mathrm{P}$ \\
\hline$A-\phi 8-L 20 \phi-C 30-11$ & M4 & & & 64.66 & 2.22 & 0.29 & 16.10 & 15.28 & $\mathrm{P}$ \\
\hline A- $\phi 8-\mathrm{L} 20 \phi-\mathrm{C} 30-12$ & M4 & & & 68.88 & - & - & 17.13 & 16.28 & $\mathrm{R}$ \\
\hline A- $\phi 12-L 5 \phi-C 15-13$ & M2 & \multirow{4}{*}{61.45} & \multirow{4}{*}{0.98} & 48.30 & 0.36 & 0.31 & 21.36 & 20.93 & $\mathrm{P}$ \\
\hline A- $\phi 12-L 5 \phi-C 15-14$ & M2 & & & 41.22 & 0.30 & 0.19 & 18.23 & 17.87 & $\mathrm{P}$ \\
\hline$A-\phi 12-L 5 \phi-C 30-15$ & M2 & & & 57.86 & 0.26 & 0.17 & 25.59 & 25.08 & $\mathrm{P}$ \\
\hline A- $\phi 12-L 5 \phi-C 30-16$ & M2 & & & 57.13 & 0.32 & 0.29 & 25.27 & 24.76 & $\mathrm{P}$ \\
\hline A- $\phi 12-L 10 \phi-C 15-17$ & M3 & \multirow{4}{*}{67.85} & \multirow{4}{*}{0.93} & - & - & - & - & - & $S$ \\
\hline$A-\phi 12-L 10 \phi-C 15-18$ & M3 & & & 70.62 & 0.84 & 0.16 & 15.62 & 14.53 & PS \\
\hline$A-\phi 12-L 10 \phi-C 30-19$ & M3 & & & 82.50 & 1.30 & 0.31 & 18.24 & 16.97 & $\mathrm{P}$ \\
\hline$A-\phi 12-L 10 \phi-C 30-20$ & M3 & & & 96.57 & 1.38 & 0.24 & 21.35 & 19.86 & $\mathrm{P}$ \\
\hline A- $\phi 12-L 20 \phi-C 15-21$ & M3 & \multirow{4}{*}{67.85} & \multirow{4}{*}{0.93} & 127.57 & 2.67 & 0.10 & 14.10 & 13.11 & PS \\
\hline$A-\phi 12-L 20 \phi-C 15-22$ & M3 & & & 116.05 & 2.45 & 0.12 & 12.83 & 11.93 & PS \\
\hline$A-\phi 12-L 20 \phi-C 30-23$ & M3 & & & 146.23 & 3.00 & 0.16 & 16.17 & 15.04 & $\mathrm{P}$ \\
\hline$A-\phi 12-L 20 \phi-C 30-24$ & M3 & & & - & - & - & - & - & $\mathrm{S}$ \\
\hline
\end{tabular}


Table 5 - Bond results of GFRP bar (type B)

\begin{tabular}{|c|c|c|c|c|c|c|c|c|c|}
\hline \multirow{2}{*}{$\begin{array}{c}\text { Specimen } \\
\text { designation }\end{array}$} & \multicolumn{3}{|c|}{ Concrete } & \multirow{2}{*}{$\begin{array}{l}F_{\max } \\
(\mathbf{k N})\end{array}$} & \multirow{2}{*}{$\begin{array}{c}s_{l p} \\
(\mathbf{m m})\end{array}$} & \multirow{2}{*}{$\begin{array}{c}s_{f p} \\
(\mathbf{m m})\end{array}$} & \multirow{2}{*}{$\begin{array}{c}\bar{\tau}_{\max } \\
\text { (MPa) }\end{array}$} & \multirow{2}{*}{$\begin{array}{c}\text { Modified } \\
\text { bond } \\
\text { stress } \\
\text { (MPa) }\end{array}$} & \multirow{2}{*}{$\begin{array}{c}\text { Failure } \\
\text { Mode }^{1}\end{array}$} \\
\hline & $\begin{array}{c}\text { Mix } \\
\text { design }\end{array}$ & $\begin{array}{c}f_{\mathrm{c}} \\
(\mathrm{MPa})\end{array}$ & $\gamma_{i}$ & & & & & & \\
\hline B- $\phi 12-L 5 \phi-C 15-25$ & M1 & 58.58 & 1.00 & 40.79 & 0.46 & 0.09 & 18.04 & 18.04 & $\mathrm{P}$ \\
\hline B- $\phi 12-L 5 \phi-C 15-26$ & M2 & \multirow{3}{*}{61.45} & \multirow{3}{*}{0.98} & 43.33 & 0.49 & 0.10 & 19.17 & 18.71 & $\mathrm{P}$ \\
\hline B- $\phi 12-L 5 \phi-C 30-27$ & M2 & & & 53.63 & 0.48 & 0.10 & 23.72 & 23.15 & $\mathrm{P}$ \\
\hline B- $\phi 12-L 5 \phi-C 30-28$ & M2 & & & 48.00 & 0.50 & 0.07 & 21.23 & 20.72 & $\mathrm{P}$ \\
\hline B- $\phi 12-L 10 \phi-C 15-29$ & M3 & \multirow{4}{*}{67.85} & \multirow{4}{*}{0.93} & - & - & - & - & - & $S$ \\
\hline B- $\phi 12-L 10 \phi-C 15-30$ & M3 & & & 62.92 & 0.81 & 0.09 & 13.91 & 12.94 & $\mathrm{P}$ \\
\hline B- $\phi 12-\mathrm{L10} \phi-\mathrm{C30}-31$ & M3 & & & - & - & - & - & - & S \\
\hline B- $\phi 12-\mathrm{L10} \phi-\mathrm{C30}-32$ & M3 & & & 76.64 & 1.50 & 0.08 & 16.95 & 15.76 & $\mathrm{P}$ \\
\hline B- $\phi 12-L 20 \phi-C 15-33$ & M5 & \multirow{4}{*}{66.38} & \multirow{4}{*}{0.95} & 97.70 & 1.77 & 0.08 & 10.80 & 10.15 & $\mathrm{P}$ \\
\hline B- $\phi 12-\mathrm{L} 20 \phi-\mathrm{C} 15-34$ & M5 & & & 99.78 & 2.31 & 0.08 & 11.03 & 10.36 & $\mathrm{P}$ \\
\hline B- $\phi 12-\mathrm{L} 20 \phi-\mathrm{C} 30-35$ & M5 & & & 107.53 & 2.01 & 0.10 & 11.89 & 11.17 & $\mathrm{P}$ \\
\hline B- $\phi 12-\mathrm{L} 20 \phi-\mathrm{C} 30-36$ & M5 & & & 104.94 & 2.71 & 0.09 & 11.60 & 10.90 & $\mathrm{P}$ \\
\hline
\end{tabular}

${ }^{\text {I }}$ Failure modes: P - Pullout; PS - Pullout and Splitting crack; R - bar rupture; S - SFRSCC shear failure 


\section{List of Figures:}

Figure 1. Schematic illustration of bond test setups: (a) Direct pullout (b) Ring (c) Splice and (d) Beam test

Figure 2 - GFRP bars: (a) Ribbed 12mm diameter (type A), (b) Sand-coated 12mm diameter (type B), (c) Ribbed $8 \mathrm{~mm}$ diameter (type $\mathrm{A})$

Figure 3- (a) Specimen's details, and (b) test setup (dimensions in mm)

Figure 4- Pullout force versus loaded and free end slip for type A of $\phi 8$ with $5 \phi, 10 \phi$ and $20 \phi$ bond lengths: (a), (b) $15 \mathrm{~mm}$ concrete cover; (c), (d) $30 \mathrm{~mm}$ concrete cover

Figure 5- Pullout force versus loaded and free end slip for type A of $\phi 12$ with 5 $\phi, 10 \phi$ and $20 \phi$ bond lengths: (a), (b) $15 \mathrm{~mm}$ concrete cover; (c), (d) $30 \mathrm{~mm}$ concrete cover

Figure 6- Pullout force versus loaded and free end slip for type B of $\phi 12$ with $5 \phi, 10 \phi$ and $20 \phi$ bond lengths: (a), (b) $15 \mathrm{~mm}$ concrete cover; (c), (d) $30 \mathrm{~mm}$ concrete cover

Figure 7- Damages on surface of the bars (type A); (b) Different damages at top and bottom of the bar (type A)

Figure 8- Influence of bar diameter of type $\mathrm{A}$ bar on the maximum average bond stress

Figure 9 - Variation of $\bar{\tau}_{\text {res }} / \bar{\tau}_{\text {max }}$ ratio

Figure 10- The comparison between the maximum average bond stress in case of 15 (C15) and 30 (C30) concrete cover

Figure 11- (a) Maximum average bond stress versus Embedment length (b) corresponding slip at loaded end for different bar type and embedment length

Figure 12- Comparison between two type of GFRP bars: (a) maximum average bond stress; (b) Pullout force versus loaded end slip for specimens with $5 \phi$ bond length

Figure 13- Average strain in the bar versus slip at loaded end: (a) $15 \mathrm{~mm}$ concrete cover (b) $30 \mathrm{~mm}$ concrete cover 


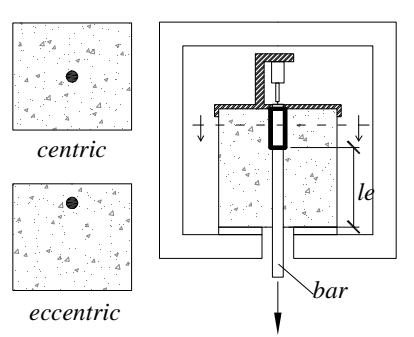

(a)

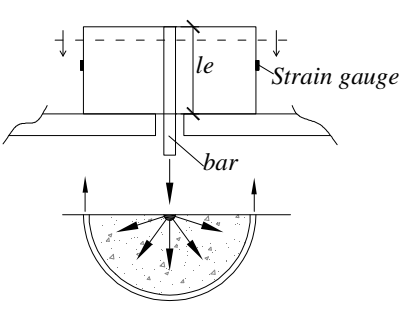

(b)

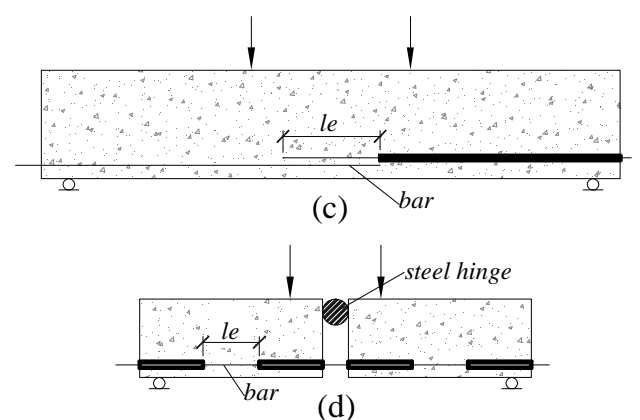

(d)

Figure 1. Schematic illustration of bond test setups: (a) Direct pullout (b) Ring (c) Splice and (d) Beam test $\left(l_{e}\right.$ : embedment length) 


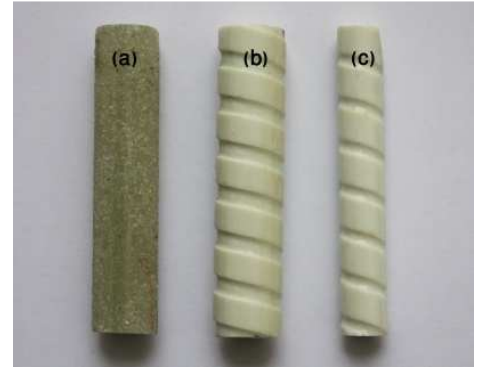

Figure 2 - GFRP bars: (a) Sand-coated $12 \mathrm{~mm}$ diameter (type B), (b) Ribbed $12 \mathrm{~mm}$ diameter (type A), (c) Ribbed 8 mm diameter (type A) 


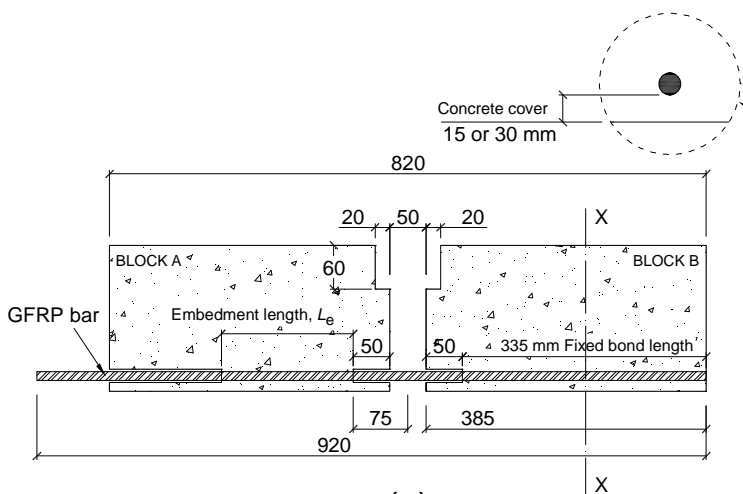

(a)

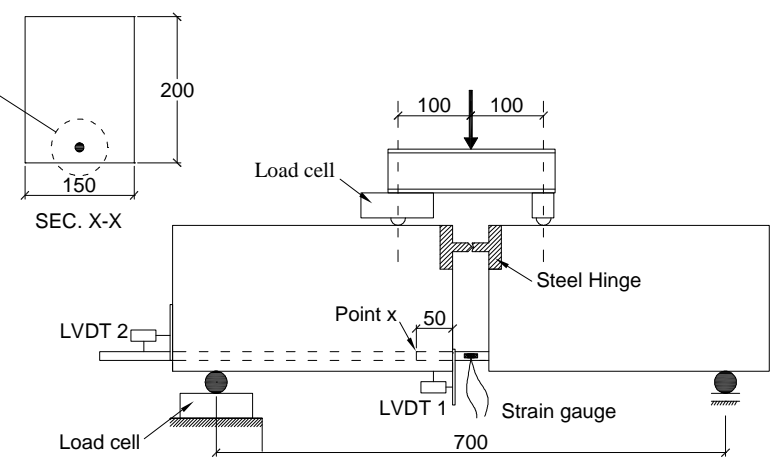

(b)

Figure 3 - (a) Specimen's details, and (b) test setup (dimensions in $\mathrm{mm}$ ) 


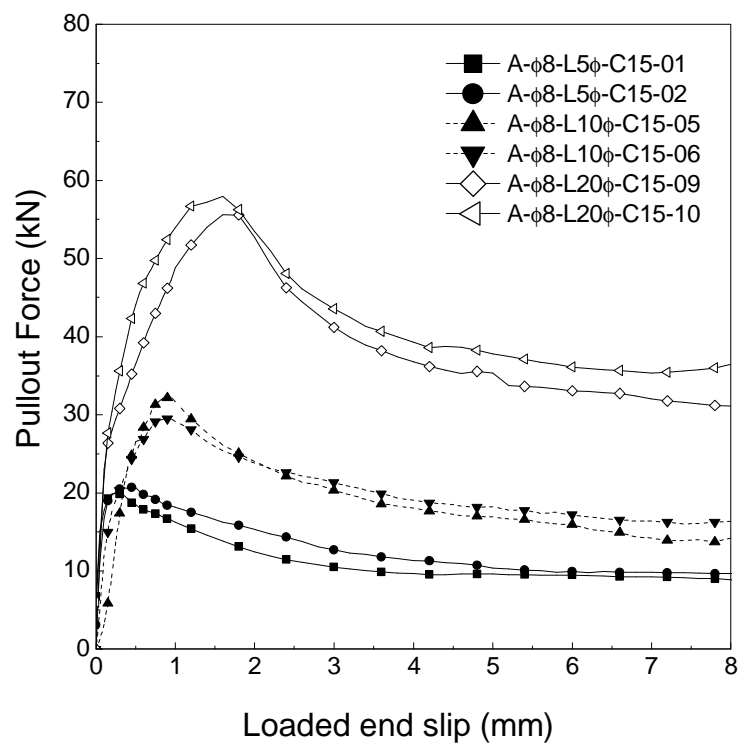

(a)

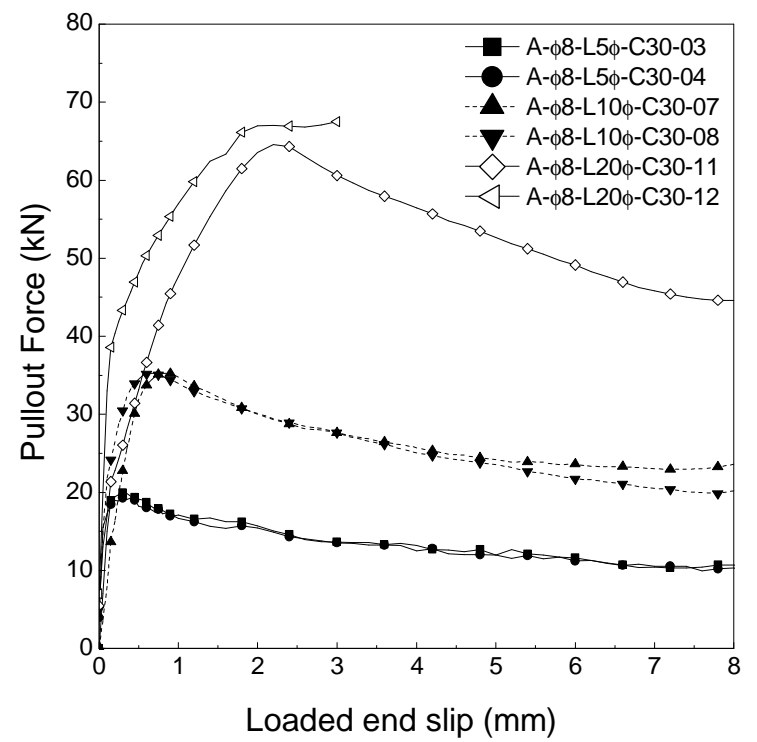

(c)

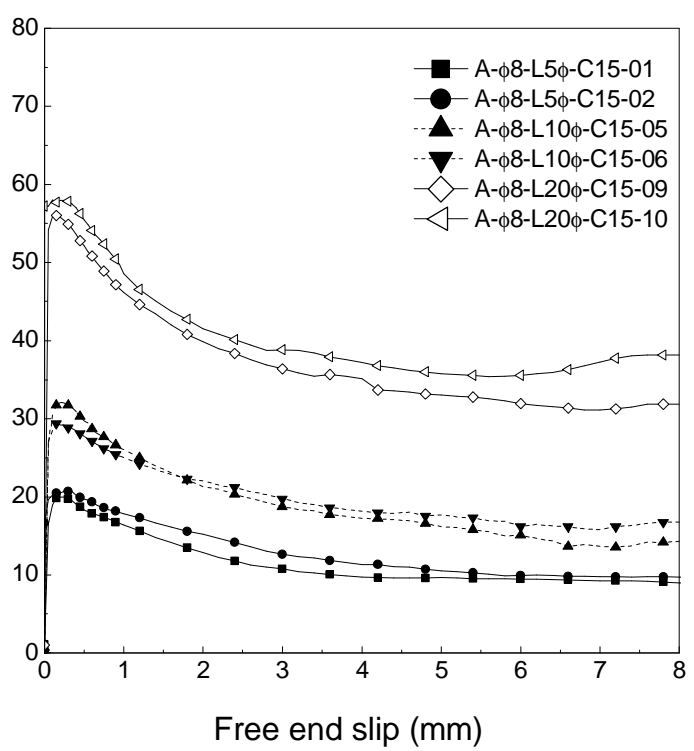

(b)

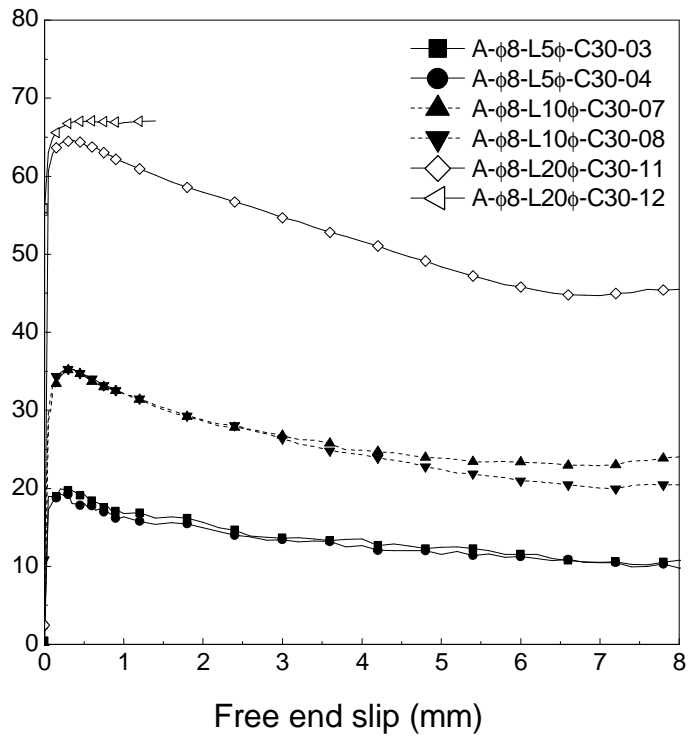

(d)

Figure 4 - Pullout force versus loaded and free end slip for type A of $\phi 8$ with $5 \phi, 10 \phi$ and $20 \phi$ bond lengths: (a)-(b) $15 \mathrm{~mm}$ concrete cover; (c)-(d) $30 \mathrm{~mm}$ concrete cover. 


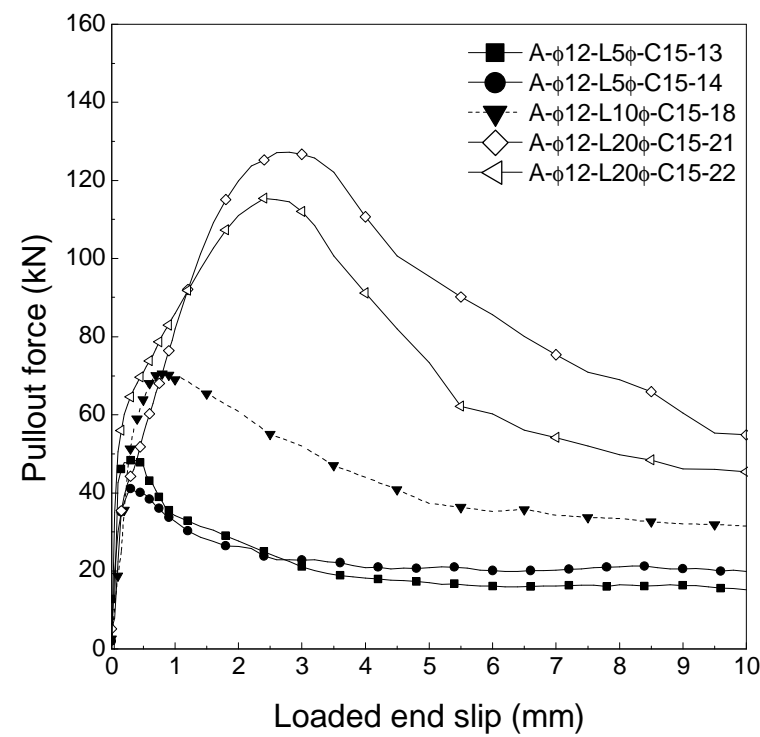

(a)

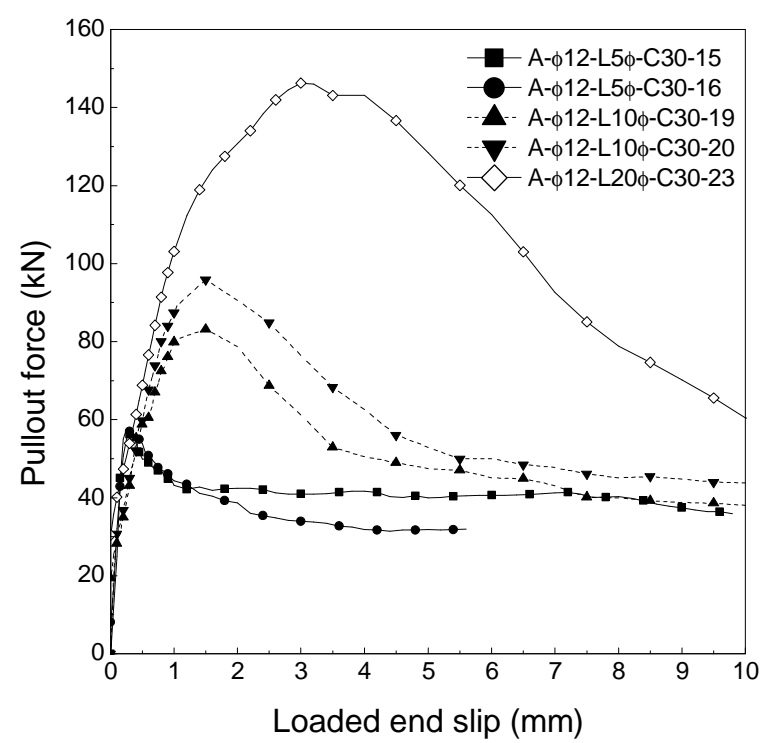

(c)

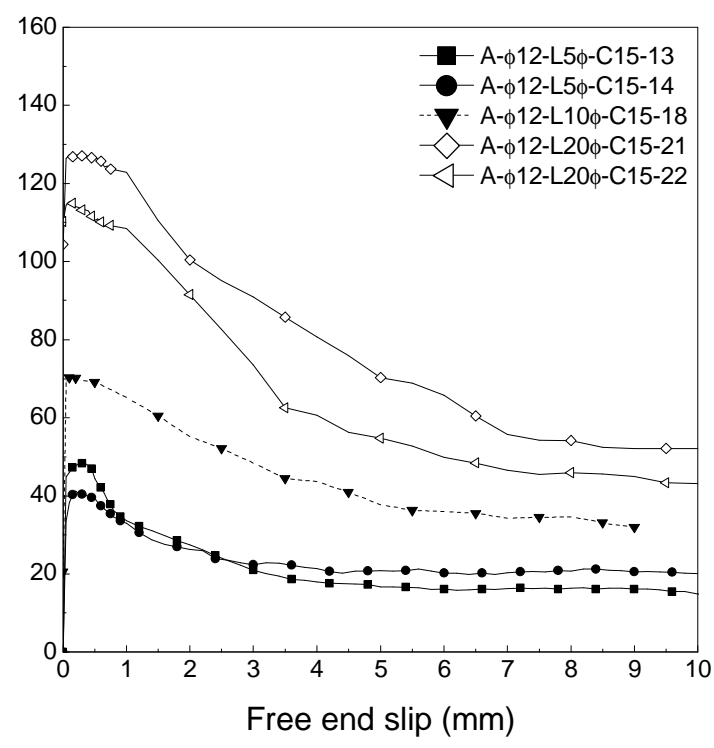

(b)

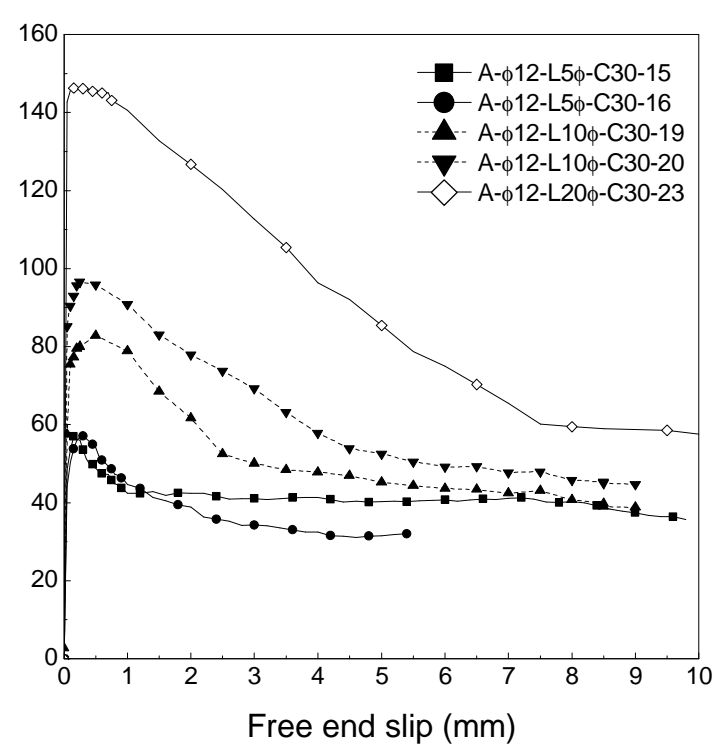

(d)

Figure 5 - Pullout force versus loaded and free end slip for type A of $\phi 12$ with $5 \phi, 10 \phi$ and $20 \phi$ bond lengths: (a)-(b) $15 \mathrm{~mm}$ concrete cover; (c)-(d) $30 \mathrm{~mm}$ concrete cover. 


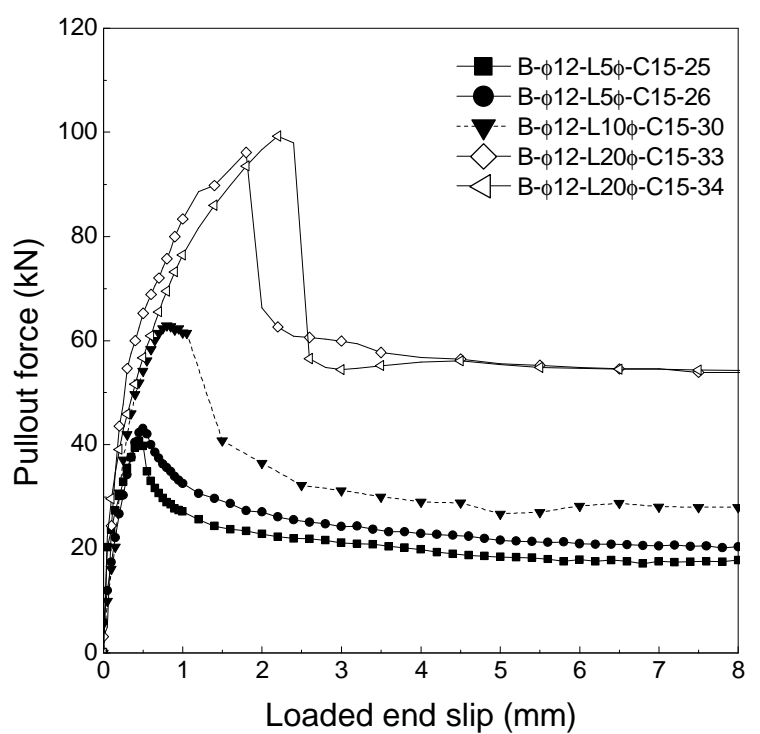

(a)

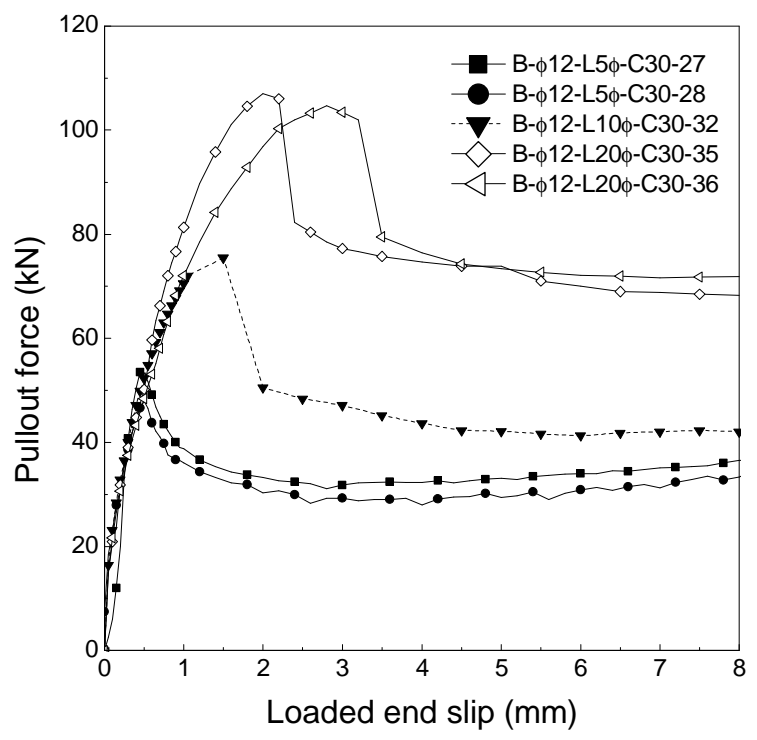

(c)

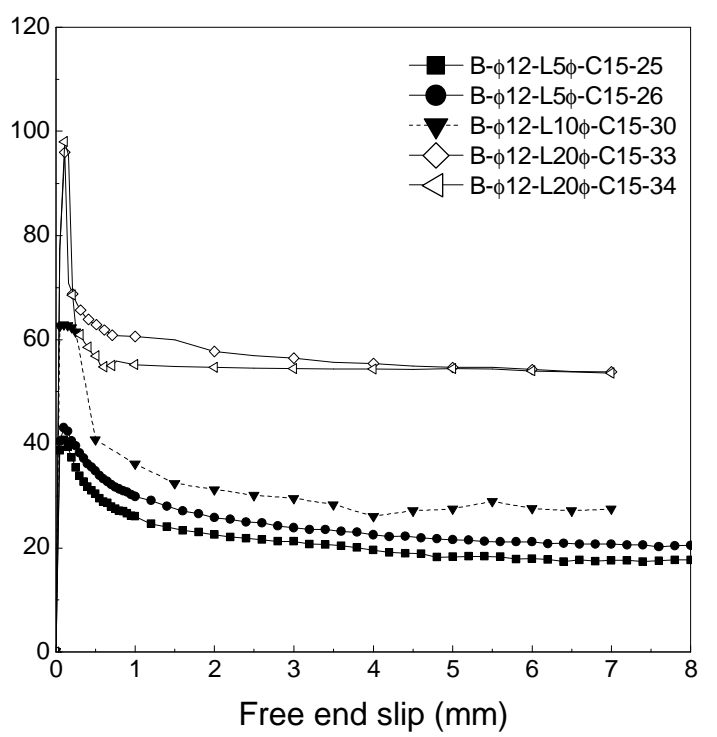

(b)

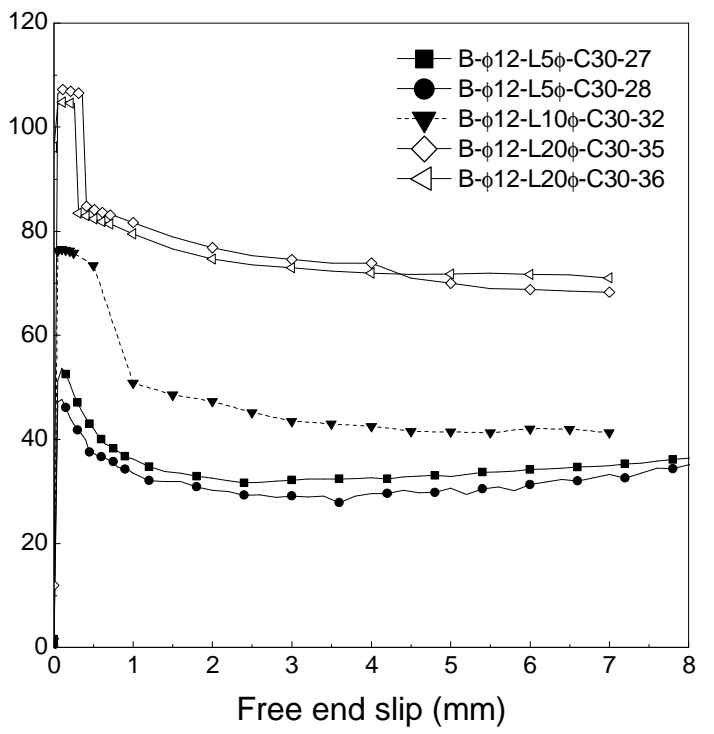

(d)

Figure 6- Pullout versus loaded and free end slip force for type B of $\phi 12$ with $5 \phi, 10 \phi$ and $20 \phi$ bond lengths: (a)-(b) $15 \mathrm{~mm}$ concrete cover; (c)-(d) $30 \mathrm{~mm}$ concrete cover. 

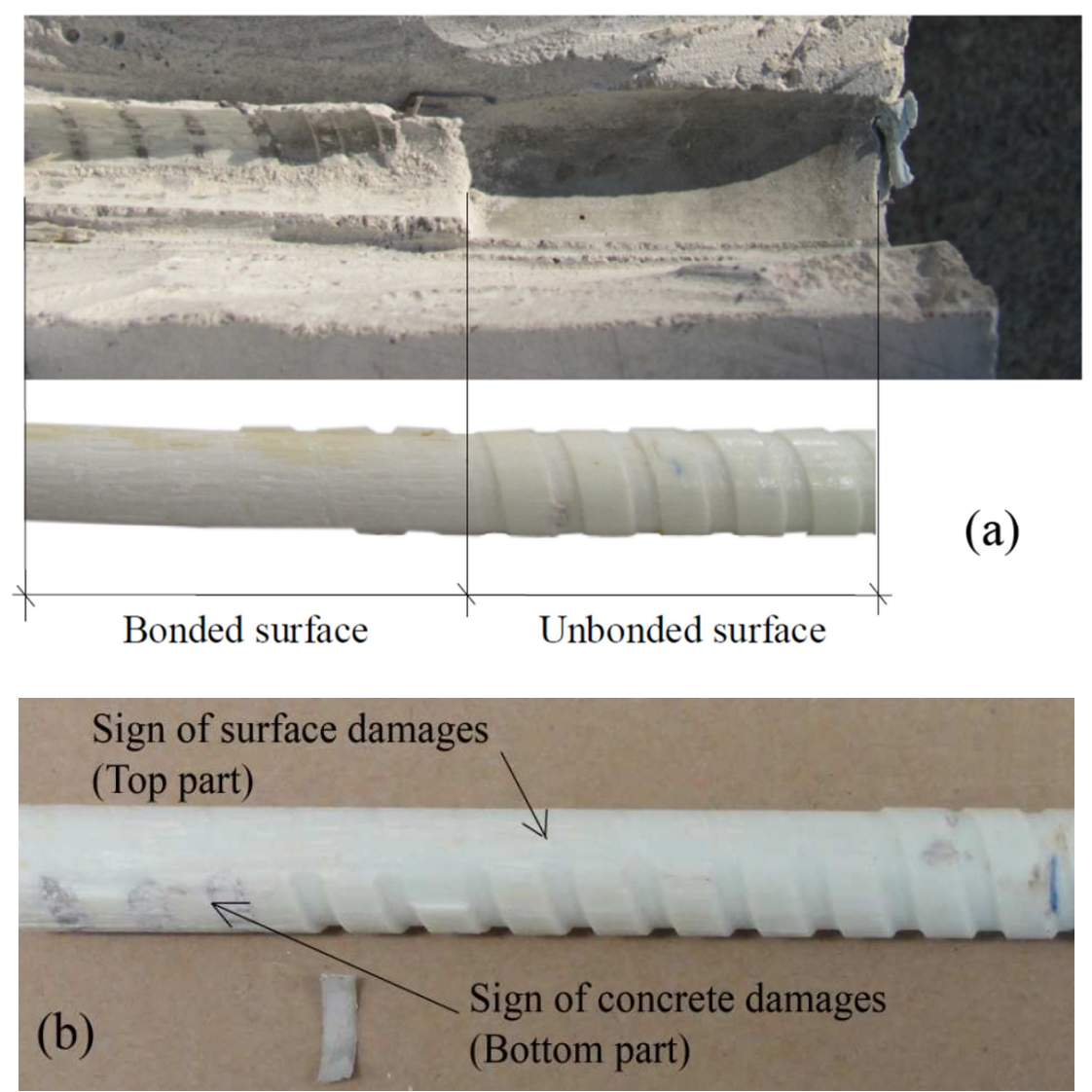

Figure 7 - Type A bar: a) appearance after specimen has been tested; b) mix damage in specimens with a splitting crack 

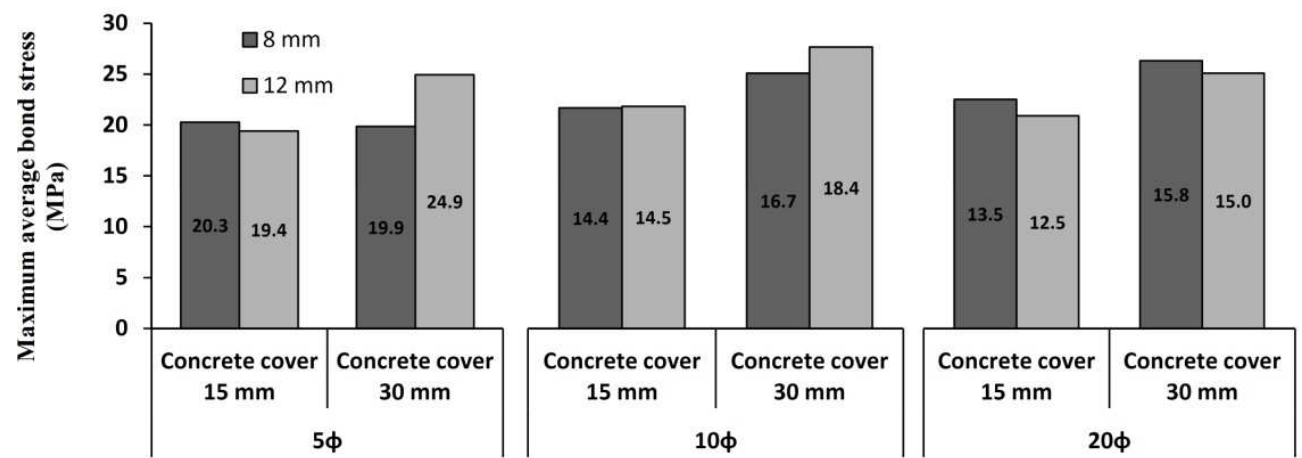

Figure 8 - Influence of bar diameter of type A bar on the maximum average bond stress 


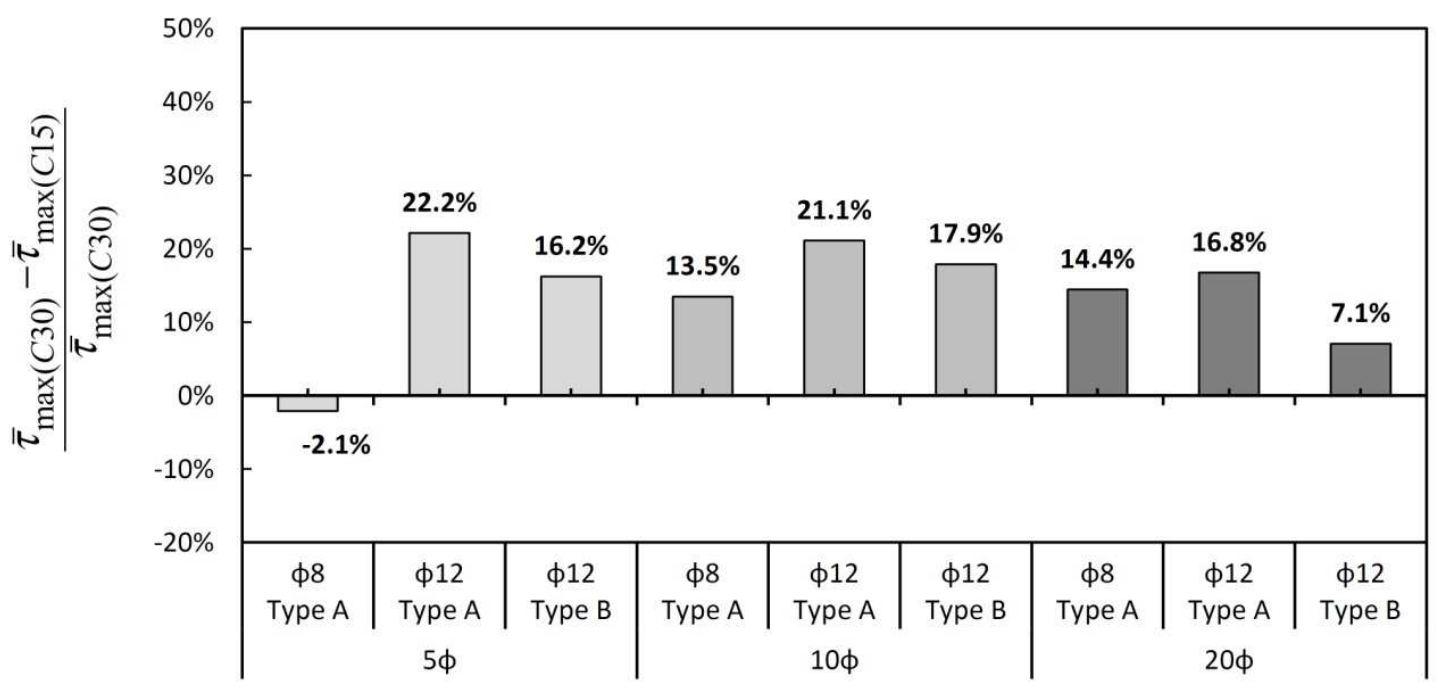

Figure 9 - The comparison between the maximum average bond stress in case of 15 (C15) and 30 (C30) concrete cover 


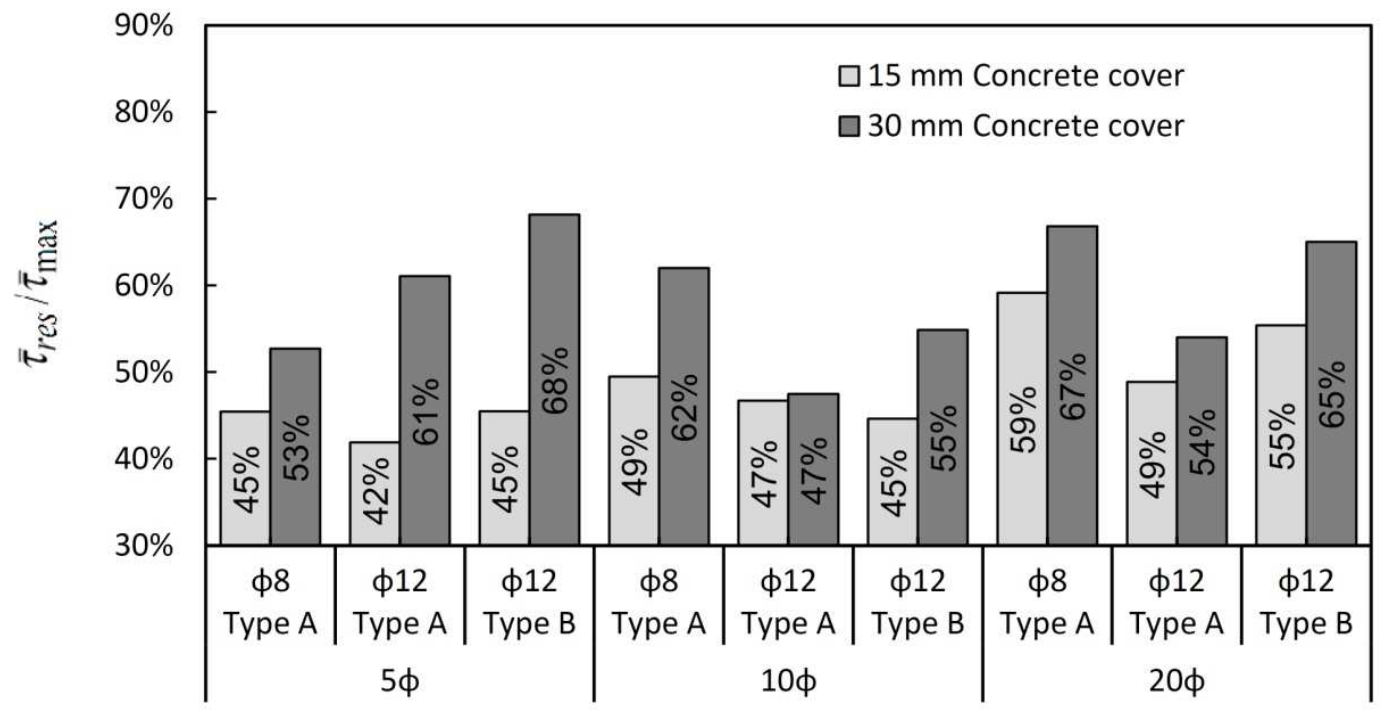

Figure 10 - Variation of $\bar{\tau}_{\text {res }} / \bar{\tau}_{\max }$ ratio 


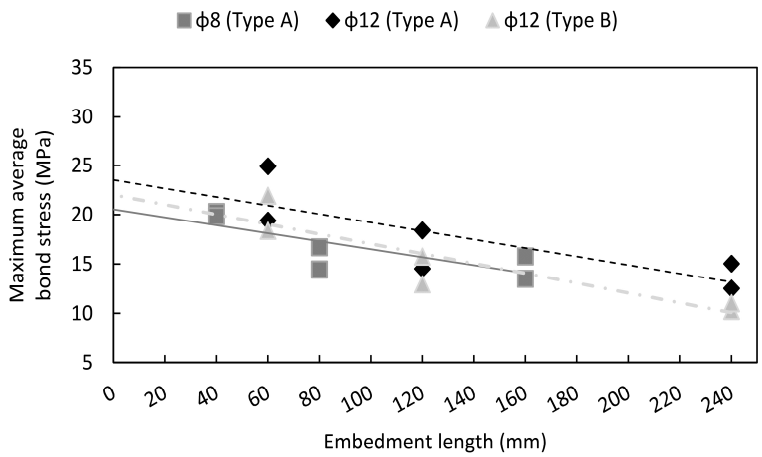

(a)

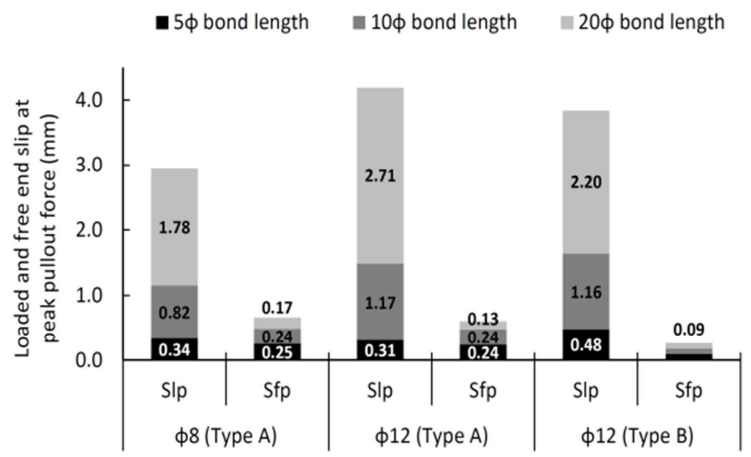

(b)

Figure 11 - (a) Maximum average bond stress versus embedment length (b) corresponding slip at loaded end for different bar type and embedment length 


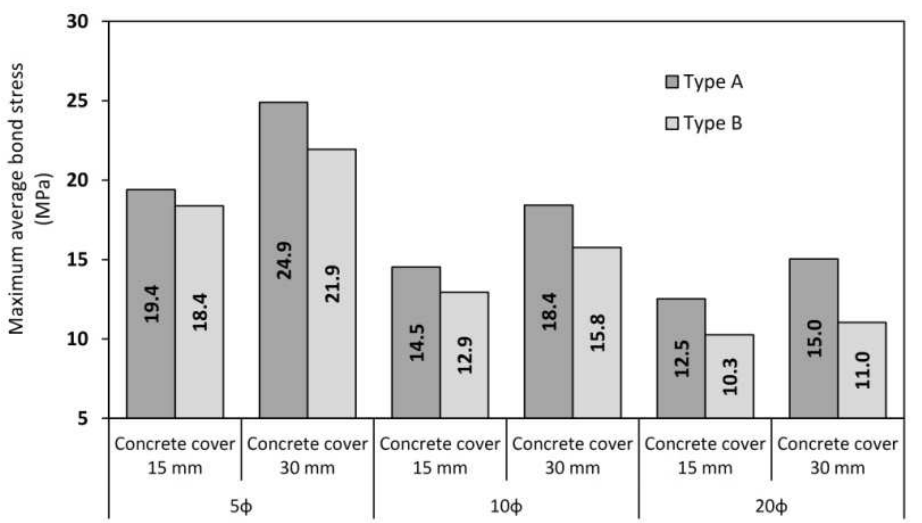

(a)

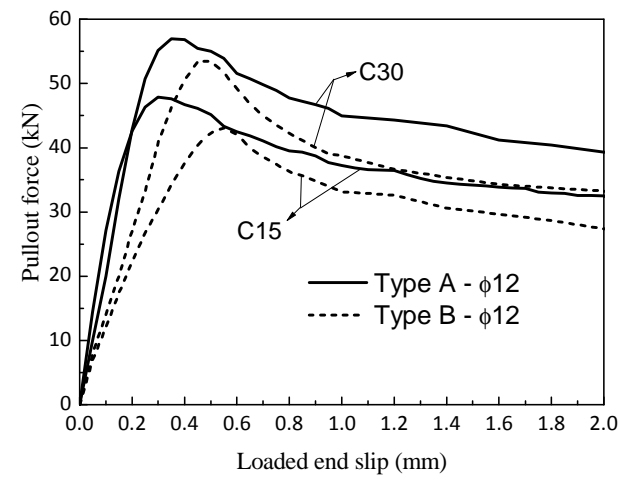

(b)

Figure 12 - Comparison between two types of GFRP bars: (a) maximum average bond stress; (b) Pullout force versus loaded end slip for specimens with $5 \phi$ bond length 


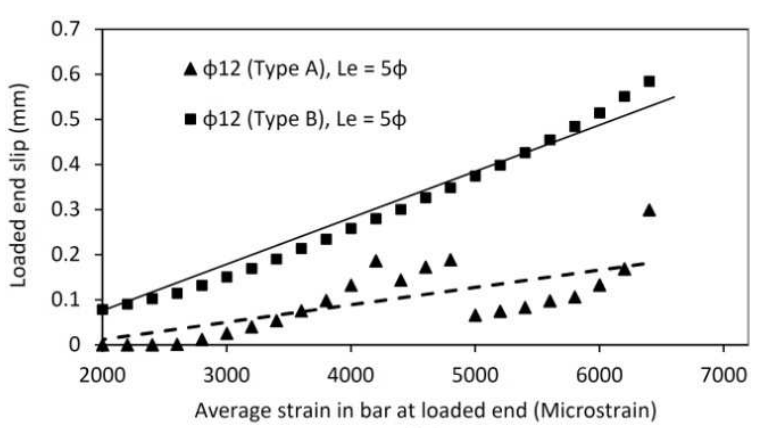

(a)

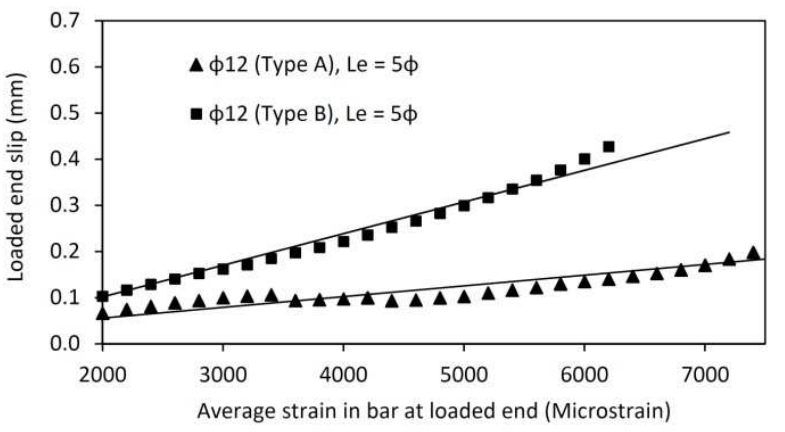

(b)

Figure 13 - Average strain in the bar versus loaded end slip: (a) $15 \mathrm{~mm}$ concrete cover (b) $30 \mathrm{~mm}$ concrete cover 


\section{NOTATION}

$A_{b}$ : Cross-section of GFRP bars;

$E_{b}$ : Modulus of elasticity of GFRP bars;

$f_{c m i}:$ Compressive strength of each concrete mix batch for preparing pullout bending specimens;

$f_{c m r}:$ Compressive strength of reference batch for modifying maximum average bond stress;

$F$ : Pullout force;

$F_{\max }:$ Maximum pullout force;

$L_{e}:$ Embedment length of GFRP bars in specimens;

$l_{f}$ : Length of discrete steel fibers;

$d_{f}$ diameter of discrete steel fibers;

$s_{f p}:$ Slip at free loaded end slip corresponding to maximum pullout force;

$s_{l p}$ : Slip at loaded end slip corresponding to maximum pullout force;

$s_{f}:$ Slip at free loaded end;

$s_{l}$ : Slip at loaded end slip;

$s_{\text {LVDTI }}$ : The values of slip recorded by LVDT_1;

$\varepsilon_{b}$ : The strain in GFRP bar measured by strain gauge;

$\gamma_{i}$ : Ratio between compressive strength of each mix batches and the compressive strength of reference batch;

$\bar{\tau}_{\text {max }}$ : Maximum average bond stress of GFRP bar;

$\bar{\tau}_{\text {res }}:$ Residual average bond stress bond stress of GFRP bar; 